\title{
Prevalence of hepatitis B surface antigen (HBsAg) positivity and its associated factors in Rwanda
}

Jean Damascene Makuza ${ }^{1 *}$ D, Jean Olivier Twahirwa Rwema², Corneille Killy Ntihabose', Donatha Dushimiyimana', Justine Umutesi ${ }^{1}$, Marie Paul Nisingizwe ${ }^{4}$, Janvier Serumondo ${ }^{1}$, Muhamed Semakula ${ }^{1}$, David J. Riedel ${ }^{3}$ and Sabin Nsanzimana ${ }^{1}$

\begin{abstract}
Background: The epidemiology of hepatitis B virus (HBV) infection in the general population in Rwanda is not well known. This study examined the prevalence of HBV surface antigen ( $\mathrm{HBsAg}$ ) positivity and associated risk factors among people aged 25 years and over in an organized national screening campaign.

Methods: This is a cross-sectional study using data from a nationwide HBV screening campaign organized by the Rwanda Biomedical Centre from March to October 2018. This campaign targeted individuals aged $>25$ years old from 24 of 30 districts of Rwanda. Sensitization was done through multimedia announcements, community health workers and local church leaders. During the campaign, a structured interview was administered by trained healthcare workers to collect information on socio-demographic, clinical and behavioral characteristics of participants; HBV screening was performed with HBsAg using enzyme-linked immunosorbent assays (ELISA) testing. Bivariate and multivariate logistic regressions were used to assess factors associated with HBsAg positivity in the screened participants.

Results: A total of 327,360 individuals were screened during the campaign. Overall 12,865(3.9\%) were HBsAg positive. The highest prevalence (4.2\%) was found in the 35-44-year-old group, but the difference from other groups was not significant (Odds Ratio [OR $=1.057,95 \%$ Confidence Interval(Cl) (0.904-1.235)]. Being male $[\mathrm{OR}=1.348,95 \% \mathrm{Cl}(1.30,1.40)]$; being single $[\mathrm{OR}=1.092,95 \% \mathrm{Cl}(1.10-1.16)]$ compared to married; a previous positive TB screening test [OR $=2.352,95 \% \mathrm{Cl}(1.63-3.39)]$; history of surgical operation $[\mathrm{OR}=1.082,95 \% \mathrm{Cl}(1.00,1.17)]$; exposure to traditional operational practices and scarification $[O R=1.187,95 \% \mathrm{Cl}(1.13,1.24)]$; and having a person in the family with viral hepatitis $[\mathrm{OR}=1.367,95 \% \mathrm{Cl}(1.21,1.53)]$ were significantly associated with HBV infection.
\end{abstract}

Conclusions: These data provide the first national estimate of the prevalence of HBsAg seropositivity and its associated factors in Rwanda. The study identified people with the highest risk of HBV infection who should be the priority of future prevention efforts in Rwanda and in similar settings.

Keywords: Hepatitis B, Prevalence, Risk factors, Rwanda

\footnotetext{
* Correspondence: makorofr@gmail.com

${ }^{1}$ IHDPC Department, Rwanda Biomedical Center, Po Box 7162, Kigali, Rwanda

Full list of author information is available at the end of the article
}

(c) The Author(s). 2019 Open Access This article is distributed under the terms of the Creative Commons Attribution 4.0 International License (http://creativecommons.org/licenses/by/4.0/), which permits unrestricted use, distribution, and reproduction in any medium, provided you give appropriate credit to the original author(s) and the source, provide a link to the Creative Commons license, and indicate if changes were made. The Creative Commons Public Domain Dedication waiver (http://creativecommons.org/publicdomain/zero/1.0/) applies to the data made available in this article, unless otherwise stated. 


\section{Background}

Viral hepatitis caused an estimated 1.34 million deaths in 2015 worldwide [1]. These deaths were as many as those caused by tuberculosis and higher than those caused by HIV [2]. Most $(720,000)$ hepatitis related deaths were due to liver cirrhosis, followed by primary liver cancer i.e. hepatocellular carcinoma (470,000 deaths) [3]. Globally, an estimated 257 million people were living with chronic hepatitis B infection (HBV) in 2015, and the global prevalence of $\mathrm{HBV}$ infection in the general population was $3.5 \%$ [4]. However, the prevalence of chronic HBV infection is much higher among people born before the HBV vaccine became available [5].

Despite the introduction of universal HBV vaccination and effective antiviral therapy, the estimated overall seroprevalence of HBV surface antigen remains high in Africa at 6.1\% [6] and the Western Pacific regions (6.2\%) [1]. According to the World Health Organization (WHO), HBV infection affects more than $5 \%$ of the local population in sub-Saharan Africa, with more than $8 \%$ in West Africa and reaching up to $15 \%$ in some areas [7]. In East African countries, only a few studies have been conducted on the epidemiology of viral hepatitis, and most of these studies focused on specific subpopulations, e.g. those living with HIV [8-13]. Data for the general populations are mostly unavailable.

In Rwanda, HBV prevalence data is only available among specific population subgroups. One study among 13,121 pregnant women in 30 sentinel sites found a prevalence of HBsAg of $3.7 \%$ [8]. A recent study of 117,258 people living with HIV (PLHIV) found a prevalence of HBsAg of $4.3 \%$ [10]. However, there are limited data on the epidemiology of $\mathrm{HBV}$ in the general population.

In order to better understand the seroprevalence of $\mathrm{HBV}$ in the general population of the country, the Rwanda Biomedical Center (RBC) and its partners conducted several HBV screening campaigns to inform HBV prevention and treatment programming in Rwanda. This article analyzed the prevalence and risk factors of $\mathrm{HBsAg}$ seropositivity among people who participated in a national hepatitis screening campaign in Rwanda.

\section{Methods}

\section{Study design}

This is a cross-sectional study. Data collection was done at the time of HBV screening using a standardized data collection tool administered by trained health care providers.

\section{Study population and recruitment of participants}

This campaign was conducted from 29 March to 26 October 2018 in 24 districts in Rwanda. These districts had been identified as having a high prevalence of HBV in an earlier brief campaign in 2017 that was conducted in all the 30 districts. The study population consisted of individuals aged 25 years and above. Sensitization on HBV screening and participants' mobilization was done through radio advertisements and with the help of community health workers before and during the screening period. All participants who attended screening sites (health centers) were screened for HBV after verbal consent was obtained.

\section{Data collection procedures}

A chart abstraction instrument (Additional file 1) was elaborated for collecting socio-demographic, clinical and behavioral data. Trained healthcare providers used registers of participants to complement information gathered from the interviews. Blood sample collection for $\mathrm{HBV}$ screening was performed by the same trained nurses and laboratory technicians. Data were extracted from laboratory request forms stored in the testing sites and entered into a database by trained health care providers.

HBV screening was done by laboratory technicians with experience in enzyme-linked immunosorbent assays (ELISA) testing. Prior to the screening campaign, a 2-week practical training session was organized for the laboratory technicians. The following procedures were followed for screening: specimens were collected at the site of enrollment and then transported to testing facilities. Testing was performed at 13 laboratories which were all 5-star accredited satellite laboratories serving as hubs of the National Reference Laboratory and distributed across all provinces of Rwanda. The 5-star laboratories are ones that achieved $95 \%$ of WHO evaluation for accreditation to provide an interim pathway for measuring, monitoring, and recognizing improvement toward the realization of international laboratory standards and subsequent application to full International Organization for Standardization (ISO) 15,189 schemes [14]. Tests were conducted using Murex ELISA for HBsAg (version 3.0). No confirmatory tests were done. All testing procedures were supervised by a team of laboratory technicians from the National Reference Laboratory of Rwanda. Data entry was done using Microsoft Excel 2013.

\section{Variables}

The primary outcome was a binary variable of HBsAg positivity, defined as "positive" if participants tested HBsAg positive, and "negative" if participants tested HBsAg negative. Independent variables were socio-demographic characteristics including age, sex, screening district, type of health insurance, and socioeconomic status (Ubudehe category). Ubudehe is a home-grown development program whereby citizens are placed into different categories by socioeconomic status as defined in accordance with Ministry of 
Local Government (MINALOC) criteria: communities periodically rank households on a scale of 1 to 4 according to their perceived poverty and vulnerability status, with a score of 1 being the most vulnerable and 4 the least vulnerable [15].

Clinical and behavioral variables were also assessed including high blood pressure, diabetes, chronic renal failure, cancer, tuberculosis, surgical operation, unhygienic traditional surgical operation practices (these include scarification, uvulectomy, intentional cutting of the body known as indasago, tattoos, and traditional dental extraction), history of blood transfusion, multiple sex partners, history of viral hepatitis in the family, and HIV status. Variables were all self-reported by participants.

\section{Statistical methods \& data analysis}

After data cleaning using Excel, they were imported and analyzed using Statistical Package for the Social Sciences (SPSS) version 20.0. In the bivariate analysis, logistic regression was used to assess the association between categorical variables and outcome. Variables that were statistically significant at the $5 \%$ level of significance were retained in the final model building. In the multivariate analysis, potential determinants of HBsAg positivity were assessed using logistic regression. Variables that were not significant were eliminated using backward stepwise method. The study considered 326,100 of 327,360 participants screened in the logistic regression analysis; 1260 participants were removed due to missing values.

\section{Ethics}

Routinely collected program data analyzed for this study are maintained by the Rwanda Biomedical Centre (RBC), Division of HIV/AIDS, STIs and Other Blood Borne Infections. The ethical procedures for the collection of these data were governed by the Medical Research Council of Rwanda, and site authorizations were obtained from the Ministry of Health for hosting sites. Secondary analyses of routinely collected data are exempt by RBC. Approval (No. 2048/RBC/2019) for utilization of the data was obtained by RBC. Verbal consent was obtained from all eligible participants to HBV screening before blood sample and interview based data collection and ethical review approval was conferred due to the routine nature of the data.

\section{Results}

\section{Study population}

Socio-demographic characteristics of this study population are shown in Table 1. The mean age of participants was 44.8 years [44.74-44.84] with the majority of participants $87,554(25 \%)$ in the 25-34-year-old group as shown in Fig. 1. The majority (68.8\%) were female, and $77.5 \%$ of participants were married. Nearly half $(45.5 \%)$ of participants were in Ubudehe category 3, and nearly all (93.6\%) participants were enrolled in the community-based health insurance (mutuelle). Among all participants, 5.6\% had been operated on at least once and $16.6 \%$ had a history of traditional surgical and scarification practice.

Table 2 shows the prevalence of HBsAg according to different characteristics among participants. The overall prevalence of HBsAg was 3.9\% (12,865/326,652). HBsAg positivity was most prevalent in the $35-44$ year-old and 45-54-year-old age groups (4.2\% in both; see also Fig. 1), in males (4.3\%), in participants in Ubudehe class 4 (5.1\%).

In the multivariable analysis, factors that remained statistically significantly associated with $\mathrm{HBsAg}$ positivity were male sex $\mathrm{OR}=1.34$ [95\% CI 1.30-1.40]; living in the Eastern province OR $=1.132$ [95\% CI 1.075-1.192]; being single OR $=1.092[95 \%$ CI 1.10-1.16] compared to married; having a history of tuberculosis $\mathrm{OR}=2.352[95 \% \mathrm{CI}$ 1.63-3.39], surgical operation OR $=1.082$ [95\% CI 1.00 1.17], or traditional operational practices and scarification $\mathrm{OR}=1.187$ [95\% CI 1.13-1.24]; and a history of viral hepatitis in the family OR $=1.367$ [ $95 \%$ CI $1.21-1.53$ ].

\section{Discussion}

This study was the first national-level study of HBsAg prevalence in Rwanda and showed that the overall prevalence of HBsAg positivity was $3.9 \%$ in the screened population. This prevalence is comparable to the $4.3 \%$ prevalence among PLHIV and the $3.7 \%$ prevalence among pregnant women in Rwanda [8, 10]. From 2015 in Rwanda, there have been several wide scale vaccination campaigns among people at risk for HBV; these campaigns may have lowered the prevalence in adults. These findings indicate that the Rwandan HBV prevalence is intermediate according to WHO criteria, as the prevalence ranges between 2 and 8\% [16]. Nearby East African countries also have prevalence ranges estimated at $2-8 \%$. For example, Kenya, Tanzania, and Ethiopia have general population prevalence reported at 2, 6, and $8 \%$, respectively $[4,13,17]$.

In addition to estimating the prevalence of HBV infection in the population screened, this study has identified different factors associated with prevalent HBV infection. Identification of risk factors is essential as it informs HBV prevention programming especially in resource-limited countries [18]. The factors associated with HBsAg positivity in this study included male sex, province of origin, and some clinical and behavioral characteristics including history of tuberculosis, exposure to blood transfusion, and viral hepatitis in the family. These factors have also been identified to be associated with HBV infection in other studies. Many of the identified factors have very low odds ratios (and may have been overpowered given the large sample size). 
Table 1 General characteristics of participants in a national HBV screening campaign in Rwanda

\begin{tabular}{|c|c|c|c|}
\hline Characteristics & All participants N (\%) & HBsAg positive N (\%) & HBsAg negative $\mathrm{N}(\%)$ \\
\hline \multicolumn{4}{|l|}{ Gender $(N=326175)$} \\
\hline Female & $224,382(68.8)$ & 7996(3.6) & $216,386(96.4)$ \\
\hline Male & $101,793(31.2)$ & $4813(4.3)$ & $96,980(95.7)$ \\
\hline \multicolumn{4}{|l|}{ Age group $(N=319302)$} \\
\hline$<35$ years old & $91,922(28.8)$ & $3737(4.1)$ & $88,185(95.9)$ \\
\hline 35-44 years old & $79,337(21.8)$ & $3321(4.2)$ & $76,016(95.8)$ \\
\hline $45-54$ years old & $61,733(21.5)$ & $3321(4.2)$ & $58,412(95.8)$ \\
\hline 55-64 years old & $50,379(18.3)$ & 1782(3.5) & $48,597(96.5)$ \\
\hline 65 years old and above & $32,965(11.6)$ & $1229(3.7)$ & $31,736(96.3)$ \\
\hline \multicolumn{4}{|l|}{ Marital status ( $N=319,302)$} \\
\hline Married & $247,437(77.5)$ & $1217(4.3)$ & $246,220(95.7)$ \\
\hline Single & 28,188(8.8) & $9813(4.0)$ & $18,375(96.0)$ \\
\hline Widow & $33,994(10.6)$ & 1213(3.6) & $32,781(96.4)$ \\
\hline Divorced & $1644(0.5)$ & $53(3.2)$ & $1591(96.8)$ \\
\hline Separated & $8039(2.5)$ & 298(3.7) & $7741(96.3)$ \\
\hline \multicolumn{4}{|l|}{ Ubudehe category $(N=318855)$} \\
\hline Category 1 (most vulnerable) & $49,886(15.6)$ & 1849(3.7) & 48,037(96.3) \\
\hline Category 2 & $119,643(36.5)$ & 4706(3.9) & $114,937(96.1)$ \\
\hline Category 3 & $149,092(45.5)$ & $5950(4.0)$ & $143,142(96.4)$ \\
\hline Category 4 (least vulnerable) & $234(0.1)$ & $12(5.1)$ & 222(94.9) \\
\hline \multicolumn{4}{|l|}{ Health Insurance* $(N=327360)$} \\
\hline Mutuelle & $303,206(93.6)$ & $11,927(3.9)$ & $291,279(96.1)$ \\
\hline RAMA & $14,708(4.5)$ & $569(3.9)$ & $14,139(96.1)$ \\
\hline MMl & $2574(0.8)$ & $109(4.2)$ & 2465(95.8) \\
\hline MEDIPLAN and other private insurances & $3465(1.1)$ & 132(3.8) & 3333(96.2) \\
\hline \multicolumn{4}{|l|}{ Province of origin $((N=315040)$} \\
\hline South & 48,994(15.6) & 2471(3.8) & $46,523(96.2)$ \\
\hline West & $89,885(28.5)$ & $3415(3.8)$ & $86,470(96.2)$ \\
\hline North & $65,824(20.9)$ & 1648(3.4) & $64,176(96.6)$ \\
\hline East & $110,337(35.0)$ & 4783(4.3) & $105,554(95.7)$ \\
\hline \multicolumn{4}{|l|}{ Diabetes $(N=326926)$} \\
\hline No & $325,059(99.4)$ & $12,765(3.9)$ & $312,294(96.1)$ \\
\hline Yes & 1867(0.6) & $82(4.4)$ & 1785(95.6) \\
\hline \multicolumn{4}{|l|}{ Hypertension ( $N=326931)$} \\
\hline No & $317,421(97.1)$ & $12,480(3.9)$ & $304,941(96.1)$ \\
\hline Yes & $9510(2.9)$ & $370(3.9)$ & $9140(96.1)$ \\
\hline \multicolumn{4}{|l|}{ Chronic Renal Failure $(N=326930)$} \\
\hline No & 326,323(99.8) & $12,648(3.9)$ & $313,675(96.1)$ \\
\hline Yes & $578(0.2)$ & 202(4.9) & $376(95.1)$ \\
\hline \multicolumn{4}{|l|}{ Cancer $(N=326901)$} \\
\hline No & $32,016(98.0)$ & $12,821(3.9)$ & $19,195(96.1)$ \\
\hline Yes & 293(0.2) & $27(4.7)$ & 266(95.3) \\
\hline
\end{tabular}


Table 1 General characteristics of participants in a national HBV screening campaign in Rwanda (Continued)

\begin{tabular}{|c|c|c|c|}
\hline Characteristics & All participants N (\%) & HBsAg positive N (\%) & HBsAg negative $N(\%)$ \\
\hline \multicolumn{4}{|c|}{ HCV infection ( $N=326193)$} \\
\hline Negative & $313,355(96.1)$ & $12,061(4.0)$ & $301,294(96.0)$ \\
\hline Positive & $12,838(3.9)$ & $777(3.5)$ & $12,061(96.5)$ \\
\hline \multicolumn{4}{|c|}{ HIV status ( $N=326913)$} \\
\hline Negative & $320,316(98.0)$ & $12,570(3.9)$ & $307,746(96.1)$ \\
\hline Yes & $6597(2.0)$ & $279(4.2)$ & 6318(95.8) \\
\hline \multicolumn{4}{|c|}{ Ever had TB $(N=326919)$} \\
\hline No & $326,581(99.9)$ & $12,813(3.9)$ & $313,768(96.1)$ \\
\hline Yes & $338(0.1)$ & $35(10.4)$ & 303(89.6) \\
\hline \multicolumn{4}{|c|}{ Ever been operated $(N=326913)$} \\
\hline No & $309,037(94.4)$ & $12,066(3.9)$ & $296,971(96.1)$ \\
\hline Yes & $17,876(5.6)$ & $781(4.4)$ & $17,095(95.6)$ \\
\hline \multicolumn{4}{|c|}{ Ever been transfused $(N=326922)$} \\
\hline No & $321,572(98.4)$ & $12,590(3.9)$ & $308,982(96.1)$ \\
\hline Yes & $5350(1.6)$ & 258(4.8) & 5092(95.2) \\
\hline \multicolumn{4}{|c|}{ Traditional operation and scarification $(N=326652)$} \\
\hline No & $272,555(83.4)$ & $10,363(3.8)$ & $262,192(96.2)$ \\
\hline Yes & $54,097(16.6)$ & 2477(4.6) & $51,620(95.4)$ \\
\hline \multicolumn{4}{|c|}{ Having more than 1 sexual partner $(N=326785)$} \\
\hline No & $318,030(97.3)$ & $12,428(3.9)$ & $305,602(96.1)$ \\
\hline Yes & $8755(2.7)$ & $416(4.8)$ & 8339(95.2) \\
\hline \multicolumn{4}{|c|}{ Viral Hepatitis in the family $(N=326882)$} \\
\hline No & $320,692(98.1)$ & $12,494(3.9)$ & $308,198(96.1)$ \\
\hline Yes & $6190(1.9)$ & $353(5.7)$ & $5837(94.3)$ \\
\hline
\end{tabular}

* Mutuelle: Community based health insurance

*RAMA: La Rwandaise Assurance Maladie: Health insurances for employees of public and private sectors

*MMI: Military Medical Insurance

*MEDIPLAN: Private insurance initiated by Insurance Company called SORAS

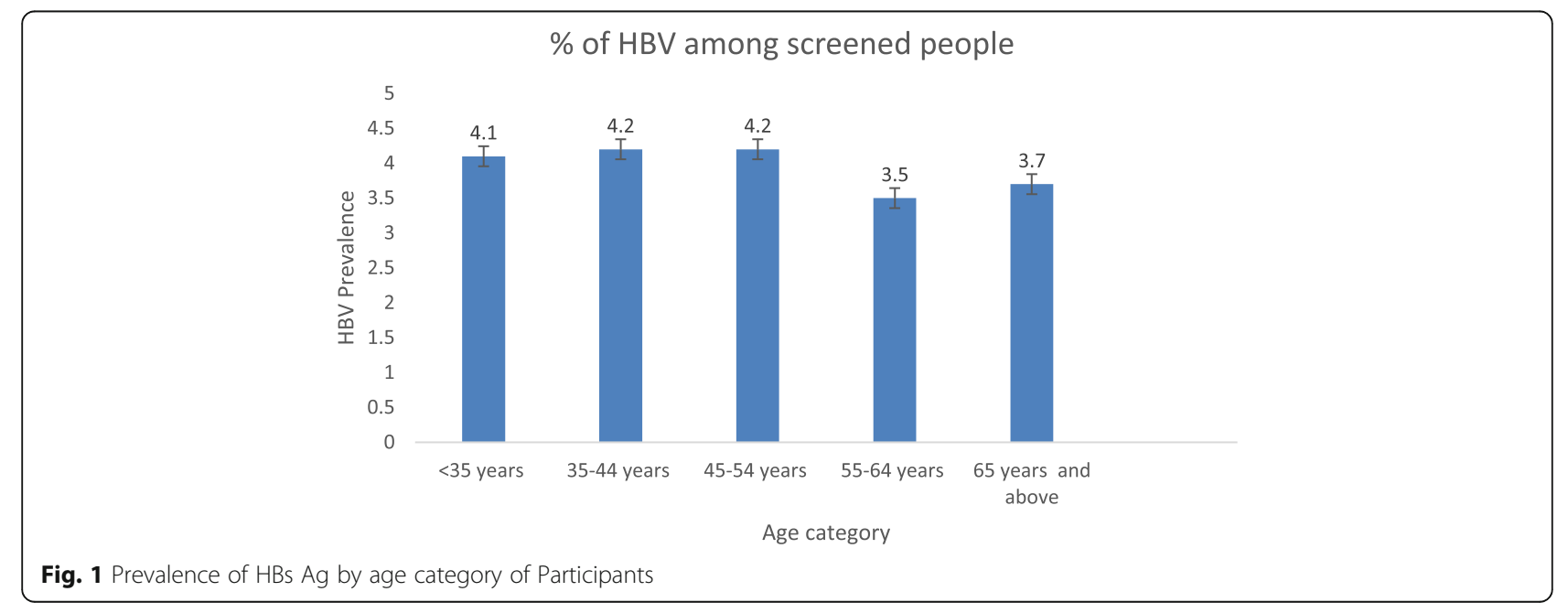


Male sex was one of demographic characteristics associated with HBsAg positivity in this study. The reasons behind this association may be that males may be more prone to high risk behaviors like sexual contact, violence and conflicts in which blood contact may occur. Other studies from Pakistan [19] and Tanzania [13] also found that male sex was associated with $\mathrm{HBV}$ infection. In Rwanda, a prior study conducted among PLHIV also found higher HBV infection among men [10].

High HBsAg prevalence was found in Eastern province with the peak prevalence in Kirehe district (8.4\%) as presented in Fig. 2. The Eastern province of Rwanda has a large number refugees and other migrants from bordering countries. It is possible that this population has a higher risk of HBV acquisition due to unhygienic living conditions, low vaccination rates, or possibly behaviors (like traditional scarification). The Eastern Province has now been targeted for future HBV vaccination campaigns.

Among risks factors found in this study, certain clinical characteristics like a history of tuberculosis, surgical operation, and traditional operational practices and scarification and a history of viral hepatitis in the family were found to be associated with HBsAg positivity. Being exposed to blood and blood products through medical and non-medical practices is the main source of HBV transmission and could be the reason why these factors were associated with $\mathrm{HBV}$ infection in this study. Previous studies have identified exposure to blood products, history of surgical operations, history of $\mathrm{HBV}$ in the family, undergoing body piercing as risks factors for HBV [20-25]. In a study conducted in Sao Paulo, Brazil HBV infection was associated with a family history of hepatitis and tattoos practicing [26] were reported as main factors associated with HBV. Over the last decade, Rwanda has made great strides in securing and testing the blood supply, and it is though that iatrogenic $\mathrm{HBV}$ exposures should continue to decline.

The results from this study provide an estimate of the prevalence of HBV infection in Rwanda based on a large number of diverse participants from different districts in the country. These estimates help to inform HBV prevention and treatment programming in Rwanda while waiting for more generalizable prevalence estimates from studies conducted on random national samples. Additionally, identification of factors associated with $\mathrm{HBV}$ in this population can allow the design and implementation of interventions targeted to the most at risk populations in Rwanda. For instance, organizers of HBV screening, prevention and treatment programs could prioritize groups that were identified to be most at-risk

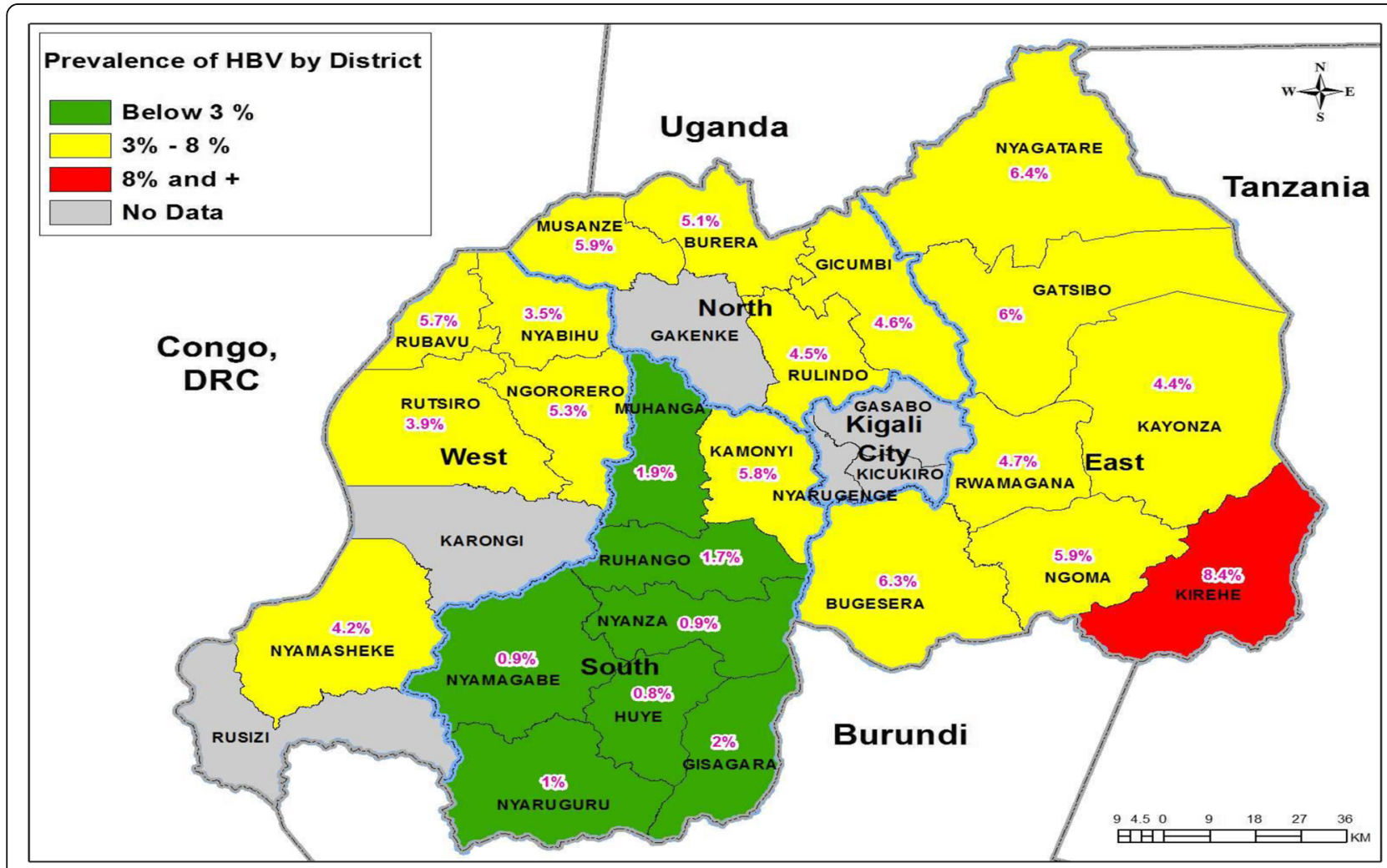

Fig. 2 Geographical repartition of prevalence of HBs Ag in Rwanda. B Kurujyishuri, JD Makuza et al. Kigali, Dec 2019. 
Table 2 Prevalence of HBsAg according to different characteristics among participants in 24 districts in Rwanda

\begin{tabular}{|c|c|c|c|c|c|c|}
\hline \multirow[t]{2}{*}{ Characteristics } & \multicolumn{2}{|l|}{ Frequencies } & \multicolumn{2}{|c|}{ Bivariate analysis } & \multicolumn{2}{|c|}{ Multivariate analysis } \\
\hline & Frequency & HBsAg positive (\%) & OR & $(95 \% \mathrm{Cl})$ & $\overline{O R}$ & $(95 \% \mathrm{Cl})$ \\
\hline \multicolumn{7}{|l|}{ Overall HBV prevalence $(N=327360)$} \\
\hline Negative & 314,420 & 96.1 & & & & \\
\hline Positive & 12,865 & 3.9 & & $(3.83-3.97)$ & & \\
\hline \multicolumn{7}{|l|}{ Gender $(N=326100)$} \\
\hline Female & 224,335 & 7996(3.6) & 1 & & 1 & \\
\hline Male & 101,765 & 4813(4.3) & 1.343 & $(1.295-1.393)$ & 1.353 & $(1.301-1.408)$ \\
\hline \multicolumn{7}{|l|}{ Age group $(N=317356)$} \\
\hline$<35$ years & 92,220 & $3737(4.1)$ & 1 & & 1 & \\
\hline $35-44$ years & 79,638 & $3321(4.2)$ & 1.030 & $(0.982-1.081)$ & 1.039 & $(0.988-1.105)$ \\
\hline $45-54$ years & 61,889 & $3321(4.2)$ & 0.956 & $(0.908-1.008)$ & 0.976 & $(0.923-1.109)$ \\
\hline $55-64$ years & 50,544 & 1782(3.5) & 0.865 & $(0.817-0.917)$ & 0.895 & $(0.841-0.952)$ \\
\hline $65+$ years & 33,065 & $1229(3.7)$ & 0.914 & $(0.856-0.976)$ & 0.923 & $(0.861-0.965)$ \\
\hline \multicolumn{7}{|l|}{ Marital status $(N=319229)$} \\
\hline Single & 28,184 & $1217(4.3)$ & 1 & & 1 & \\
\hline Married & 247,377 & $9813(4.0)$ & 0.915 & $(0.861-0.973)$ & 1.064 & $(0.975-1.161)$ \\
\hline Widow, Divorced and separated & 43,668 & $15,643.6)$ & 0.823 & $(0.763-0.889)$ & 0.985 & $(0.927-1.047)$ \\
\hline \multicolumn{7}{|l|}{ Ubudehe category $(N=318784)$} \\
\hline Category 1 & 49,881 & $1849(3.7)$ & 1 & & 1 & \\
\hline Category 2 & 119,622 & 4706(3.9) & 1.051 & $(1.007-1.124)$ & 1.019 & $(0.994-1.112)$ \\
\hline Category 3 & 149,047 & $5950(4.0)$ & 1.053 & $(1.024-1.139)$ & 1.03 & $(0.996-1.114)$ \\
\hline Category 4 & 234 & $12(5.1)$ & 1.372 & $(0.784-2.515)$ & 2.127 & $(0.765-2.463)$ \\
\hline \multicolumn{7}{|l|}{ Health Insurance $(N=323879)$} \\
\hline Mutuelle & 303,140 & $11,927(3.9)$ & 1 & & 1 & \\
\hline RAMA & 14,701 & $569(3.9)$ & 0.983 & $(0.902-1.071)$ & 0.893 & $(0.815-0.978)$ \\
\hline MMl & 2573 & $109(4.2)$ & 1.08 & $(0.891-1.310)$ & 1.013 & $(0.828-1.238)$ \\
\hline MEDIPLAN and other private insurances & 3465 & 132(3.8) & 0.967 & $(0.812-1.152)$ & 0.874 & $(0.717-1.067)$ \\
\hline \multicolumn{7}{|l|}{ Province of screening $(N=313945)$} \\
\hline North & 65,812 & 2471(3.8) & 1 & & 1 & \\
\hline West & 89,857 & $3415(3.8)$ & 1.013 & $(0.961-1.068)$ & 0.993 & $(0.941-1.049)$ \\
\hline South & 48,963 & 1648(3.4) & 0.893 & $(0.863-0.951)$ & 0.956 & $(0.892-1.025)$ \\
\hline East & 110,334 & $4783(4.3)$ & 1.162 & $(1.105-1.221)$ & 1.132 & $(1.075-1.192)$ \\
\hline \multicolumn{7}{|l|}{ Diabetes $(N=326,851)$} \\
\hline No & 324,985 & $12,765(3.9)$ & 1.000 & & & \\
\hline Yes & 1866 & $82(4.4)$ & 1.124 & $(0.900-1.404)$ & & \\
\hline \multicolumn{7}{|l|}{ High Blood pressure $(N=326856)$} \\
\hline No & 317,348 & $12,480(3.9)$ & 1.000 & & & \\
\hline Yes & 9508 & $370(3.9)$ & 0.989 & $(0.890-1.099)$ & & \\
\hline \multicolumn{7}{|l|}{ CRF $(N=326855)$} \\
\hline No & 322,718 & $12,648(3.9)$ & 1.000 & & & \\
\hline Yes & 4137 & 202(4.9) & 1.258 & $(1.091-1.451)$ & & \\
\hline \multicolumn{7}{|l|}{ Suffering from Cancer $(N=326826)$} \\
\hline No & 326,248 & $12,821(3.9)$ & 1 & & & \\
\hline Yes & 578 & $27(4.7)$ & 1.198 & $(0.814-1.764)$ & & \\
\hline
\end{tabular}


Table 2 Prevalence of HBsAg according to different characteristics among participants in 24 districts in Rwanda (Continued)

\begin{tabular}{|c|c|c|c|c|c|c|}
\hline \multirow[t]{2}{*}{ Characteristics } & \multicolumn{2}{|l|}{ Frequencies } & \multicolumn{2}{|c|}{ Bivariate analysis } & \multicolumn{2}{|c|}{ Multivariate analysis } \\
\hline & Frequency & HBsAg positive (\%) & $\mathrm{OR}$ & $(95 \% \mathrm{Cl})$ & $\mathrm{OR}$ & $(95 \% \mathrm{Cl})$ \\
\hline \multicolumn{7}{|c|}{ HCV infection(326193) } \\
\hline Negative & 313,355 & $12,061(4.0)$ & 1 & & 1 & \\
\hline Positive & 12,838 & $777(3.5)$ & 0.879 & $(0.816-0.946)$ & 0.880 & $(0.812-0.924)$ \\
\hline \multicolumn{7}{|c|}{ HIV status ( $N=326838)$} \\
\hline Negative & 320,242 & $12,570(3.9)$ & 1 & & 1 & \\
\hline Positive & 6596 & $279(4.2)$ & 1.081 & $(0.958-1.220)$ & 0.835 & $(0.541-1.290)$ \\
\hline \multicolumn{7}{|c|}{ Ever had TBC $(N=326844)$} \\
\hline No & 326,506 & $12,813(3.9)$ & 1.000 & & 1.000 & \\
\hline Yes & 338 & $35(10.4)$ & 2.828 & $(1.992-4.015)$ & 2.352 & $(1.634-3.385)$ \\
\hline \multicolumn{7}{|c|}{ Ever been operated $(N=326838)$} \\
\hline No & 308,966 & $12,066(3.9)$ & 1.000 & & 1.000 & \\
\hline Yes & 17,872 & $781(4.4)$ & 1.124 & $(1.044-1.211)$ & 1.082 & $(1.000-1.171)$ \\
\hline \multicolumn{7}{|c|}{ Ever been transfused $(N=326847)$} \\
\hline No & 321,500 & $12,590(3.9)$ & 1.000 & & 1.000 & \\
\hline Yes & 5347 & 258(4.8) & 1.244 & $(1.096-1.411)$ & 1.122 & $(0.980-1.284)$ \\
\hline \multicolumn{7}{|c|}{ Ever been traditionally operated $(N=326577)$} \\
\hline No & 272,493 & $10,363(3.8)$ & 1.000 & & 1.000 & \\
\hline Yes & 54,084 & 2477(4.6) & 1.214 & $(1.161-1.270)$ & 1.187 & $(1.133-1.244)$ \\
\hline \multicolumn{7}{|c|}{ Having more than 1 sexual partner $(N=326710)$} \\
\hline No & 317,958 & $12,428(3.9)$ & 1.000 & & 1.000 & \\
\hline Yes & 8752 & $416(4.8)$ & 1.227 & $(1.110-1.356)$ & 1.074 & $(0.968-1.191)$ \\
\hline \multicolumn{7}{|c|}{ Viral Hepatitis in the family $(N=326807)$} \\
\hline No & 320,622 & $12,494(3.9)$ & 1.000 & & 1.000 & \\
\hline Yes & 6185 & $353(5.7)$ & 1.493 & $(1.339-1.665)$ & 1.367 & $(1.221-1.531)$ \\
\hline
\end{tabular}

including people with a history of TB, transfusions, and those from families with a history of HBV infection.

This study has strengths and several limitations. The study strength is its very large sample size and high coverage of 24 of the 30 districts in Rwanda (80\%). However, the study population was not randomly selected and did not include Kigali city, so the prevalence results may not be generalizable to the whole country. There is also a possibility of selection bias, as people who participated in the screening program may have been more likely to have current symptoms, already know their HBV status, or be more likely to be HBV-infected. This study was aimed at individuals aged 25 years and older; the prevalence of $\mathrm{HBV}$ is likely higher in this group than in those under 25 years in Rwanda, as childhood HBV vaccination programs were begun in 2002. Future studies will need to determine the prevalence among the population less than 25 years old. Another bias may have been introduced by encouraging older individuals to come for testing, which may have resulted in an unequal age distribution. This study relied on chart review and self-reported information for clinical variables (e.g. HIV status) which may have led to misclassification through recall bias. There were also a limited number of variables available for analysis in the chart (e.g. HBV vaccination status), limiting the number of factors and confounders that could be included in the analysis. Finally, this study relied on HBsAg testing to determine prevalence of active HBV infection. Therefore, participants with acute infection or other chronic carriers may have been missed, thus underestimating the total burden of $\mathrm{HBV}$ disease. Without liver function testing or fibrosis data, subjects could not be assessed for the impact of chronic HBV infection. Despite these limitations, this study provides valuable baseline prevalence estimates to inform HBV programming in Rwanda and identifies groups for focused prevention efforts. Future studies using random sampling techniques may give a more complete estimation of the national prevalence. 


\section{Conclusion}

This study shows that HBV is an intermediate epidemic in the studied population in Rwanda. The findings are similar to little available data on HBV in the region and may be applicable in other similar settings. These results have also identified groups of people with the highest HBV risk in Rwanda. More studies are needed in order to have people that should be prioritized in prevention interventions.

\section{Additional file}

Additional file 1: Interview guide. (DOCX $128 \mathrm{~kb}$ )

\section{Abbreviations}

Cl: Confidence Interval; ELISA: Enzyme-Linked Immunosorbent Assays; GAVI: Global Alliance for Vaccines and Immunization; HBsAg: Hepatitis B Surface Antigen; HBV: Hepatitis B virus; HIV/AIDS: Human Immunodeficiency virus/ Acquired Immunodeficiency Diseases Syndrome; MEDIPLAN: Private insurance initiated by Insurance Company called SORAS; MINALOC: Ministry of Local Government; MMI: Military Medical Insurance; OR: Odd Ratio; PLHIV: People Living with HIV; RAMA: La Rwandaise Assurance Maladie: Health insurances for employees of public and private sectors; RBC: Rwanda Biomedical Center; SPSS: Statistical Package for the Social Sciences;

TB: Tuberculosis; WHO: World Health Organization

\section{Acknowledgements}

We are especially thankful to the participants in this campaign who provided the data used in this study. This study would not have been possible without them. We would also like to thank the providers from hospitals and health centers where the screening took place. We also thank the Ministry of Health and Rwanda Biomedical Center (RBC) staff and different partners for their generous assistance and support. Special acknowledgement to Mr. Barnabbe Kurujyushuri for his role producing the map of Geographical repartition of prevalence of $\mathrm{HBs} \mathrm{Ag}$ in Rwanda presented in the manuscript.

\section{Funding}

This activity was funded by the Government of Rwanda through the ministry of health. The funder has no direct involvement in study design and data collection. The design of the study, analysis, interpretation of data and writing the manuscript were conducted independently by authors.

\section{Availability of data and materials}

The datasets generated during the current study are not publicly available but are available from the corresponding author on reasonable request.

\section{Authors' contributions}

MJD, JOTR, NCK, UJ, DSM, JS, MPN, MS, SN and DJR developed the study protocol and study design. MJD, JOTR, NCK, UJ and JS collected the data. MJD and MS did the data analysis and developed the figure and tables. All authors participated in interpretation of the data. MJD did the literature review and wrote the first draft of the manuscript. All authors reviewed, provided critique and provided also approval of the manuscript.

\section{Ethics approval and consent to participate}

The ethical procedures for the collection of these data were governed by the Medical Research Council of Rwanda and site authorizations were obtained from the Ministry of Health for hosting sites. Secondary analyses of routinely collected data are exempt by the Rwanda Biomedical Center. Approval (No. 2048/RBC/2019) for utilization of the data was obtained by RBC. Verbal consent was obtained from all eligible participants to HBV screening before blood sample and interview based data collection and ethical review approval was conferred due to the routine nature of the data.

\section{Consent for publication}

Not Applicable

\section{Competing interests}

This study used routine data collected by Rwanda Biomedical center, there is no conflict of interest with any person.

\section{Publisher's Note}

Springer Nature remains neutral with regard to jurisdictional claims in published maps and institutional affiliations.

\section{Author details}

${ }^{1}$ IHDPC Department, Rwanda Biomedical Center, Po Box 7162, Kigali, Rwanda. ${ }^{2}$ Department of Epidemiology, Johns Hopkins Bloomberg School of Public Health, Baltimore, USA. ${ }^{3}$ Institute of Human Virology, University of Maryland School of Medicine, Baltimore, USA. ${ }^{4}$ School of Population and Public Health, University of British Columbia, Vancouver, Canada.

Received: 1 February 2019 Accepted: 23 April 2019

Published online: 03 May 2019

\section{References}

1. World Health Organization, Global hepatitis report, 2017. 2017.

2. WH Organization, "Viral hepatitis: a hidden killer gains visibility." 2017.

3. Ringehan M, Mckeating JA, Protzer U, Mckeating JA, Protzer U. Viral hepatitis and liver cancer. Phil Trans R Soc. 2017;B 372:20160274.

4. Zampino R, et al. Hepatitis B virus burden in developing countries. World Gastroenterol. 2015;21(42):11941-53.

5. Upreti SR, et al. Prevalence of chronic hepatitis B virus infection before and after implementation of a hepatitis $B$ vaccination program among children in Nepal. PMC. 2015;32(34):4304-9.

6. Spearman CW, et al. Hepatitis B in sub-Saharan Africa: strategies to achieve the 2030 elimination targets. lancet Gastroenterol Hepatol. 2017;2(12):900.

7. Lemoine M, Eholié S, Lacombe K. Reducing the neglected burden of viral hepatitis in Africa: strategies for a global approach. J Hepatol. 2015;62(2): 469-76.

8. Mutagoma M, et al. Hepatitis B virus and HIV co-infection among pregnant women in Rwanda. BMC Infect Dis. 2017;17(618):1-7.

9. Kateera F, et al. Hepatitis B and C seroprevalence among health care workers in a tertiary hospital in Rwanda. Trans R Soc Trop Med Hyg. 2015; 109(3):203-8.

10. Umutesi J, et al. Prevalence of hepatitis B and $C$ infection in persons living with HIV enrolled in care in Rwanda. BMC Infect Dis. 2017;17(1):1-7.

11. Rusine J, et al. High Seroprevalence of HBV and HCV infection in HIVinfected adults in Kigali, Rwanda. PLoS One. 2013;8(5):1-8.

12. Nyamusi MM, M'Imunya JM, Muvunyi CM, Habtu M. Factors Associated with Hepatitis B Surface Antigen Seropositivity among Pregnant Women in Kigali, Rwanda: A Cross Sectional Study. J Comm Pub Health Nursing. 2017; 3:192.

13. Miller WC, Shao JF, Weaver DJ, Shimokura GH, Paul DA, Lallinger GJ. Seroprevalence of viral hepatitis in Tanzanian adults. Trop Med Int Heal. 1998;3(9):757-63.

14. Messele T, et al. The World Health Organization African region laboratory accreditation process. Am J Clin Pathol. 2010;134(3):393-400.

15. M. of F. and E. P. (MINECOFIN) [Rwanda] National Institute of statistics of Rwanda (NISR), "Rwanda household, integrated survey, living conditions," 2015.

16. Hou J, Liu Z, Gu F. Epidemiology and prevention of hepatitis B virus infection. Int J Med Sci. 2005;2(1):50-7.

17. Lampertico $P$, et al. EASL 2017 clinical practice guidelines on the management of hepatitis B virus infection. J Hepatol. 2017:67(2):370-98.

18. Franco E, Bagnato B, Marino MG, Meleleo C, Serino L, Zaratti L. Hepatitis B: epidemiology and prevention in developing countries. World J Hepatol. 2012:4(3):74-80.

19. Khan F, et al. Hepatitis B virus infection among different sex and age groups in Pakistani Punjab. Virol J. 2011;8(1):225.

20. Shedain PR, Devkota MD, Banjara MR, Ling H, Dhital S. Prevalence and risk factors of hepatitis B infection among mothers and children with hepatitis $B$ infected mother in upper Dolpa, Nepal. BMC Infect Dis. 2017;17(1):1-9.

21. Huang $C$, et al. Prevalence and risk factors of hepatitis $C$ among former blood donors in rural China. Int J Infect Dis. 2012;16(10):e731-4.

22. Hayes $\mathrm{MO}$, Harkness GA. Body piercing as a risk factor for viral hepatitis: an integrative research review. Am J Infect Control. 2001;29(4):271-4. 
23. Mohamed HI, et al. Hepatitis C, hepatitis B and HIV infection among Egyptian prisoners: Seroprevalence, risk factors and related chronic liver diseases. J Infect Public Health. 2013;6(3):186-95.

24. Gorar ZA, Butt ZA, Aziz I. Risk factors for bloodborne viral hepatitis in healthcare workers of Pakistan: a population based case-control study. BMJ Open. 2014;4(7):1-7.

25. Li X, et al. Hepatitis B virus infections and risk factors among the general population in Anhui Province, China: an epidemiological study. BMC Public Health. 2012;12(1):272.

26. Valdiane $L$, et al. Major article epidemiological study of hepatitis $B$ and $C$ in a municipality with rural characteristics: Cássia dos Coqueiros, State of São Paulo, Brazil. Rev Soc Bras Med Trop. 2015;48(6):674-81.

Ready to submit your research? Choose BMC and benefit from:

- fast, convenient online submission

- thorough peer review by experienced researchers in your field

- rapid publication on acceptance

- support for research data, including large and complex data types

- gold Open Access which fosters wider collaboration and increased citations

- maximum visibility for your research: over $100 \mathrm{M}$ website views per year

At $\mathrm{BMC}$, research is always in progress.

Learn more biomedcentral.com/submissions 